\title{
6.6. Guided Self-Exploration as a "Narrative Machinery" that Produces Intelligible Subjects
}

We see that this institutional arrangement that is constituted by an intensive counseling and a portfolio-guided self-assessment guides the young person to a process self-assessment. It puts the service user in a position in which he analyses his past life, defines certain characteristics of his personality, unfolds his motivations and his interests in order to make emerge a professional project and to examine its viability according to the actual conjunctures on the labor market. It incites the young person to perform a "work on oneself", to develop a desire for a specific professional future appearing open and uncertain to himself. Nevertheless, the portfolio work unfolds itself in an area of tension between institutional demands (for instance specific pre-conditions to enter a specific apprenticeship) and individual self-thematization. The young person is invited to see himself with the eyes of employers, to integrate a specific vocabulary into his own self-descriptions. One's own conception of the self is molded within the categories that are relevant for getting a job, and these categories are taken up for guiding the attention during the process of biographical introspection, they are "used" for the interpretation of own experiences. This amounts to a kind of "biographical work" (Gubrium and Holstein 1998), In which the young person integrates new experiences into his own self-description by means of specific institutionally provided interpretation patterns. It is through this activity that the young person develops self-descriptions that are "intelligible" for other interaction fields - in this case - the world of work. The portfolio work attempts to show hidden competencies, previous experiences, and so on, and tries to make them useable, utilizable for the transition to employment through specific practices of valuation (see chapter 6.3.4.) Personal counselors encourage the participants to perform an interpretation of their biography and their previous experiences that is geared towards recognizing specific resources and competencies and that can be integrated into their professional selves, for instance, in their selfpresentation during recruitment interviews. Private life-world experiences are reassessed form the perspective of the requirements of a potential profession. This encouragement tries to create a link between two spheres where previously no link existed: between the life-worlds experiences of youngsters and the "world of work", having its own economies of recognition, its own orders of worth and it' s own relevancies. The portfolio can be seen as a form of "biography-generator" (Hahn 1998, see chapter 4), an "institutional incitement to speak" (Foucault, 1978: 67), in which the young persons are invited to re-tell their experiences, and to re-interpret them from the background of the relevancies of the world of work. Hahn defines biography generators as historically contingent devices "that urge the person to account for himself, to present his life-course, also rough acts of selection and fictionalization, into an autobiographical pattern" (Hahn 1987: 22). Hahn describes that mod- 
ern dispositives of discipline and control have played a crucial role in the making of narrative identity: "especially Foucault, but also in a different way, Elias has demonstrated that modern civilization is tied to processes of increased self-control which are increasingly internalized" (Hahn 1987: 22, own translation). Just like in a religious confession - where an unsparing truthfulness towards oneself is bound to lead to a form of self-knowledge that is meant to lead to a self-improvement and a better self-containment - the portfolio aims at inciting the young person to think about himself, to observe himself and to disclose and reflect his own life and his own learning process. Just like in the religious confession, the findings of these introspections have to be communicated, written down, and are eventually used for the fashioning of socially mediated self-presentation.

\subsubsection{Activating a Biographical "Care" for the Self}

We see that the portfolio contributes to the "transmission of macro and mesostructures into micro-sociological - meaning life-course decision and biographical actions of individuals during transitions between life-phases" (Struck 2001: 22). As described by Leisering, the complex interdependency of an individual's life-courses and institutions ask from individuals a "biographical far-sightedness" (Leisering 2004). In the portfolio, young people are incited to develop biographical reflexivity, the portfolio - so one could contend, activates a biographical preoccupation with the future, and installs a planificatory posture towards one's own biography: "Who could I be?" "What Job fits my personality?" "What options do I have - under the current labor-market conditions?". The job choice process, as depicted by in the portfolio comes with an individualistic hue - the pronominal form, the "I" that speaks from every page and every phrase, the "active voice" form depicts the process of job choice as an "individual self-project", as a kind of choice biography. The initial demand to write down three "dream jobs" on the one side deliberately abstracts from and ignores both the strict regulation of the occupation-education link of the Swiss apprenticeship system and on the other side possible internal limitations, for instance the self-elimination of lower-class youth from specific, more demanding apprenticeships. As such it may rather enhance existing class-based inequalities rather than counter then. In a certain sense, the portfolio is appealing to the (unequally distributed) "projective element of Agency" (Emirbayer/Mische 1998: 962) as it calls upon the young participants to develop representations of possible future selves, and incites the young persons to produce narratives of possible futures that are realist and realizable and that "keep the road" in front of the evaluations of the labor-market. In chapter 6.4 I have proposed to conceive the task of the Motivational Semesters as a preparation for the evaluative tests of the labor market. Within the theoretical framework of the sociology of conventions, the process of recruitment, and more precisely of a job interview has been conceived 
as a test where a person is evaluated according to some standardized repertoire of evaluation. The fashioning of "accepted" integration narratives, the description of one's own experiences and biographical experiences from the Background of the evaluative repertoire of a potential employer is not only mediated through the portfolio, but relies on a whole range of exercises (e.g. the training of self-presentation skills, the preparation of applications and CVs, and the incorporation of the adequate vocabulary to pertain as a publicly qualified person in the "tests" with which young people are confronted when entering the labor market).

As one professional describes his work with the portfolio, "the hard work is to make them explain why they think that this adjective corresponds to themselves, that means, they have to give examples and explain situations, why they think they are like this or like that". Young people learning to describe themselves and to justify their own capacities and competencies the evaluative frameworks of employers can be seen as a process of learning adequate forms of self-presentation. The portfolio and the creation of specific ways of presenting oneself is an act of submission and a means of control. The condition for becoming a subject is - if one follows Judith Butler and Michel Foucault - the iterated subjection to a specific symbolic order that defines and limits the space in which the subject's identity is formed. The formation of the subject being according to Judith Butler, based on subordination and of recognition through others. The self-presentation in the portfolio can be interpreted as an act of subordination, that aims at producing a marketable self, a self that is "intelligible" and recognizable by the symbolic orders of the labor market. Participants are addressed as managers of their own labor-power, they are called to experience themselves as "competent" and to "write" these competencies down in order to make them "readable" for specific gate-keepers. The institutional injunction is a biographical one (Duvoux 2009) and amounts to the injunction to expose yourself to the demands of a social world, to relate somehow to the demands of social life and produce self-descriptions that are intelligible and compatible with it at the risk of social exclusion. This process corresponds to what in biographical research is referred to as "biographical reflexivity" or "biographicity" (Alheit and Dausien: 2000: 405) thus the subjective processes in which socially embedded actors are interpreting their biographical trajectory and revise, re-see, and re-judge their projects at central biographical turning points. If transitions can be described - from a subjective side as a "temporal articulation of the 'subjective' (or the biographical) with the structural" (Dubar 1994: 283, own translation), the organisational technologies described clearly foster these processes through inducing the young persons to project themselves into a highly structured opportunity space. Within this process, the norm of autonomy plays a central role. As described in chapter 6.5.3 and 6.5.4, young persons are addressed as individual biographical choosers, professional futures are displayed as outcome of an individual process of choice. The described processes of self-exploration that aim at putting the indi- 
vidual into a specific, planificatory projective relationship towards itself operates from the background of an institutionalized norm of autonomy. It is this norm of autonomy that produces an intense and continuous self-scrutiny and self-evaluation. The focus on individuality serves as a guiding norm that urges "to discover who we really are, to realize our potentials and shape our lifestyles, we become tied to the project of our own identity and bound in new ways into the pedagogies of expertise" (Rose: 1993: 93). This focus on individuality is strongly linked to emergence of the modern life-course.

The institution of the life-course, and the self, infused with the idea of individual authorship of its biography is thus the outcome of a process in which persons are meant to operate the participation in different "interaction fields" (Levy 1996). As such, the communication with the personal counselors in the motivation semesters is a social system that fosters a potential inclusion in the subsystem of the economy, that - as the theory of functional differentiation describes, decides on their formal membership definitions itself. Individualized counseling, the use of self-assessment instruments as well as the contractualised individual integration agreements react to a breakdown of communication (young persons generally do not dispose of clear, compatible self-descriptions that would foster inclusion) or to "tensions" between the psychic system of the youngsters and the functional system of the economy (young persons do not display the "right" self-descriptions allowing an inclusion) and tries to transform them into communication. The reference point of the practices at the SeMo that aim at producing intelligible subjects are those "discursively articulated norms of recognizability" (Buschmann/Alkemeyer 2017: 20) that are embedded in the epistemic matrix of the used instruments and in the doings and sayings of the welfare professionals. 